\title{
Integrating Oneself into a Medical School Curriculum
}

\author{
Audrey A. Vasauskas ${ }^{1}$ (B)
}

Published online: 25 September 2015

(C) International Association of Medical Science Educators 2015

There is much discussion within medical school faculty and administration regarding the integration of basic sciences and clinical sciences in the undergraduate medical curriculum. However, every faculty member was at one time not yet a faculty member. This commentary will focus on the integration of oneself into a new academic environment while meeting the challenges of fusing basic and clinical sciences within that context. "New" could mean moving from one institution to another, updating a curriculum, or changing to a new curriculum entirely. Specifically, for me, new is the transition from post-doctoral fellow to assistant professor. Here, I will address my experience in transitioning into an assistant professor position, the integration of my teaching style into the institution's teaching curriculum, and importantly, how my research experience has shaped my attempts to integrate the basic and clinical sciences.

I arrived at my current institution by way of a post-doctoral fellowship at another medical school. I spent four and a half years with my nose to the grindstone, heavily working at the bench while writing grant applications and papers. During this time, I also had the opportunity to teach within the medical school and also to observe the curriculum updates occurring at that institution. The dual experiences of research and teaching have proven invaluable in my transition to faculty at my new institution. I was able to place my teaching experiences into a new context, and my research experience has greatly aided me in integrating the basic sciences within a clinical context. Additionally, my enthusiasm and interest for subject matter is made stronger through the application of my basic science

Audrey A. Vasauskas

avasauskas@acomedu.org

1 Alabama College of Osteopathic Medicine, Dothan, AL, USA knowledge with the knowledge and experience of our clinical faculty. I am hopeful this is the same observation that my students make.

In starting my new position, my level of excitement was high, as was my anxiety. Although I had some teaching experience, it definitely did not carry with it the same level of responsibility that I would now face. To aid my integration into this new environment, three areas of focus became clear. First, I would have to "learn the institution." This does not simply mean orienting into the new space, computer systems, etc. This is something much more involved. Secondly, I would have to "learn the material." A Ph.D. degree does not impart you with all the knowledge. Instead, a basic scientist usually knows a great deal about a singular subject in their research area. However, we also know how to learn - and how to do it quickly and efficiently. Finally, I would have to "learn to integrate." In this case, I mean how to integrate the basic sciences, a subject with which we are intimately involved, into the larger clinical relevance. This can be a daunting task for anyone, but for a basic scientist who has pondered minute details of a single protein in a cell signaling cascade, this can be downright scary. The following discussion addresses each of these points.

The first step in my integration process has been learning the institution. This is clearly a different place than from where I transitioned. The curriculum is different, and the faculty and staff are different. The entire personality of the institution is different. I first took the time to learn how the curriculum functions: the class schedules, how exams work, and who the course directors are. Importantly, I spent a lot of time with the curriculum assessment director, mainly learning how to use the learning management system (LMS) that the institution uses. Most institutions now use some sort of LMS. With curriculum updates that use lectures, small groups, practical clinical skills, and team-based learning, the use of an LMS is a 
necessity to maintain a schedule, grading, and sanity for all involved. This LMS is literally my best friend. Spending the time straight away to learn how to access my (and other faculty members') teaching schedule, the students' academic schedule, and how to upload materials has saved me hours in the long run. This is especially invaluable now as I serve as a course director for the first time.

This brings up another facet of learning the institution. It seems obvious, but many people do not take the time to get to know the other faculty, especially senior faculty. These people are gold when transitioning to a new environment. Junior faculty will help ease the transition by letting you know the ins and outs of the institution: who has the strong personalities, where you are supposed to be for academic meetings, and where the best lunch spots are. Senior faculty will aid you in your teaching, giving feedback and assessing deficiencies. Senior faculty have a wealth of knowledge, and I try to spend some time each week speaking to them about my lectures, clinical cases, and future topics. Remember that in many cases, someone coming out of a post-doc is aware of the most recent studies and data in their particular field. It is not only the new faculty that benefit from faculty interaction with one another. Lively, informative discussions can often take place while building teaching cases. I have found that getting to know the faculty really aids in planning lectures, enhances my teaching, and hopefully makes the course block stronger.

Transitioning oneself into a new faculty position usually presents with a number of non-teaching responsibilities as well. In addition to teaching and possibly research tasks, faculty are involved in committees, interview processes, course directing, continuing education, academic pursuit, and community outreach. Many post-doctoral fellows do not appreciate or do not know how much time assistant professors spend in meetings, committees, and with other responsibilities outside of the classroom or research. My new institution is no different in this regard. Within a month of my new position, I had served in some capacity in every area listed above. Additionally, my new institution has a huge presence in the local community, and faculty are encouraged to take part in this outreach. Thus, time management plays a huge role in the transition to faculty. Fortunately, post-doctoral research is a preparatory tool for this. In my research, I often had multiple experiments running, talks or lectures to prepare, and laboratory meetings to attend. Learning to properly budget time and resources during my post-doc has really made this aspect of my transition easier. Make a list. Check it twice. Seriously, each month, I make a list of long- and short-term "to-do" items. The list is updated daily as new tasks present themselves, and items are crossed out as I accomplish them. I then add major accomplishments to my $\mathrm{CV}$, in order to keep track of things to make a promotion application easier in several years' time. Just as it was in a post-doc, tracking accomplishments and managing time each day makes the days more productive and organized. I highly recommend this approach to any post-doc that has not set it in motion already. While the tasks may be different, the time management skills are transferrable.

The second step in my integration has been learning the material. This is not meant at all as flippant. As a Ph.D. student and then post-doctoral fellow, I focused on a singular subject for long periods of time. Yes, of course I also knew the background and had some contextual clinical relevance, but for the most part, the bulk of detailed subject material sits in my binders from years 1 and 2 of graduate school. In other words, I have to set a great deal of time aside to review material and build my lectures. Planning is absolutely key. Giving yourself enough time to re-master material is also paramount. With our training, basic scientists are able to assimilate a great deal of technical information in a somewhat short time period. This has proven to be extremely helpful for me in teaching large blocks of material. I have had to answer difficult questions in front of a large group of students. I am not going to lie; this can be excruciatingly nerve-racking. Speaking at large conferences certainly aided me in the experience with answering difficult questions. However, the breadth of information within a clinical context can make answering medical students' questions even more challenging. If I am unsure of an answer, I simply tell the students we will discuss it at the next class meeting or to come see me in the office. It is important to avoid giving out potentially misleading information. I always remind myself that it is a learning experience for me as well. Students teach me every day; their questions and concerns guide me on what must be covered in greater detail. They also catch every mistake I make. Rather than getting discouraged, I remind myself that while I did not catch the mistake, I will learn from it and students will benefit. My biggest take-away from the start of my career here is to start early on lectures; they always take longer than you think to put together and remaster material as much as possible. Plus, during heavy teaching loads, a steady stream of students will be at your door, so you will probably have less time during the day to work on lectures. Take this into account when planning as well.

Coming full circle, the final step in my transition has been learning to integrate the basic and clinical sciences. The concept of integration of basic and clinical training is indeed recognized as invaluable for a strong medical education [1-3]. I am extremely pleased that I wrote a number of grant applications in graduate school and during my time as a post-doc. Because of the recent emphasis on "bench-to-bedside," writing a proposal forces basic scientists to place their research into a larger clinical scenario. As a biomedical science researcher, every aspect of my research was tied back to the clinical benefit for patients. Indeed, bench-to-bedside is a phrase heard consistently throughout many halls of research $[4,5]$, reiterated by numerous articles that come up in a literature search of the phrase. While not dealing with specific 
clinical scenarios, training in these thought processes is crucial. This experience has taught me to see how the basic science fits within the larger clinical picture. Writing proposals will benefit anyone planning on an academic career, even if teaching (and not research) is your primary responsibility! The process of writing grant proposals has had multiple benefits for me, not least of which is the jump-start it gave me in integrating my teaching with the clinical sciences. For example, in a recent cardiovascular systems block, I contributed heavily to an integrated basic-clinical science session based on my former research. I used current scientific literature on a mouse knock-out model to build a case and then relate it back to the clinical aspect (the latter part was planned with a clinical faculty member). Working with clinical faculty on these integrated sessions has been very beneficial and is discussed below.

Clinical faculty have clinical experience and knowledge. Basic science faculty have scientific experience and knowledge. I still have much to learn. This will come from experience. This will also come from working closely with the clinical faculty. In my experience thus far, in order to have an integrated curriculum, the basic and clinical science faculty must work together closely to seamlessly weave the two subject areas together. In preparing my lectures, my primary focus remains on the basic science aspect. I also integrate mini-cases at the end of each lecture with questions using an audience response system ((ARS) "clickers"), allowing the students to discuss the cases with one another before answering the questions. At my current institution, a number of basic science and clinical science faculty deliberately work together to integrate their respective subject matter. When I first arrived, I was particularly struck by the relationship that the clinical and basic science faculty have in this regard. The effort to integrate basic and clinical sciences is apparent with the organization of interconnected curriculum activities $[6,7]$. The main stages of student interaction are within the combined integrated sessions. These sessions organized by more senior faculty allow the basic science faculty to work together across various disciplines and also to work closely with the clinical faculty, especially during the planning stages. The sessions are effective in integrating knowledge for students, hopefully leading to long-term retention of material.

Beyond the obvious benefits for medical student education, this type of integration lends itself to another, unexpected benefit. Due to the very nature of preparing integrated medical scenarios, basic science and clinical faculty must work together to organize, formulate cases and questions, and present the case material in the integrated session. As the learning curve is steep when adjusting to a medical school curriculum, this has made the transition to new faculty a smooth one. New faculty are exposed to different personalities, teaching styles, and ways of thinking. Additionally, we are exposed to complicated medical scenarios, furthering our own knowledge.

Moving from one position to another is challenging but can be exhilarating if taken from the perspective that one is not just joining a new team but rather integrating oneself into a new environment. Always keeping in mind three areas of focus: learning the institution, learning the material, and learning to integrate, I continue to transition successfully. Everything that I have done in my career comes with me as I embark as a new faculty member. Keeping in mind that experience and knowledge are carried forward, and integration of oneself into a medical school curriculum is a learning experience that can be beneficial to all parties involved.

\section{References}

1. Kulasegaram KM, Martimianakis MA, Mylopoulos M, Whitehead CR, Woods NN. Cognition before curriculum: rethinking the integration of basic science and clinical learning. Acad Med. 2013;10: 1578-85.

2. Dahle LO, Brynhildsen J, Behrbohm Fallsberg M, Rundquist I, Hammar M. Pros and cons of vertical integration between clinical medicine and basic science within a problem-based undergraduate medical curriculum: examples and experiences from Linkoping, Sweden. Med Teach. 2002;3:280-5.

3. Bockers A, Mayer C, Bockers TM. Does learning in clinical context in anatomical sciences improve examination results, learning motivation, or learning orientation? Anat Sci Educ. 2014;1:3-11.

4. Morgan M, Barry CA, Donovan JL, Sandall J, Wolfe CD, Boaz A. Implementing 'translational' biomedical research: convergence and divergence among clinical and basic scientists. Soc Sci Med. 2011;7: 945-52.

5. Phagocytes and the "bench-bedside interface". N Engl J Med, 1968; 18: 1014-6.

6. Wright B, Hernandez, MJ., Creation and implementation of a two year preclinical curriculum using multiple teaching approaches at a new osteopathic medical school, in Experiemental Biology. 2014, FASEB J: San Diego CA.

7. Hernandez MJ, Riggs K, Wright B, McManus C, Baker SD, El-Sawi N. Challenges and opportunities in the implementation of a paperless curriculum at a new osteopathic medical school, in Experimental Biology. 2014, FASEB J: San Diego CA. 